\title{
Closure planning challenges associated with mining adjacent to large creek lines
}

\author{
P Bussemaker Rio Tinto, Australia \\ KL Pang Rio Tinto, Australia \\ P Barnes Rio Tinto, Australia \\ CL Latham Rio Tinto, Australia \\ F McClenaghan Rio Tinto, Australia
}

\begin{abstract}
This paper presents a case study of closure surface water management for mined pits located adjacent to two large creeks in the Pilbara region of Western Australia. The mining footprint presented some significant closure challenges, with pits, waste dumps and land bridges located adjacent to creeks. Hydrological flood modelling of rare and extreme floods affecting both pre-mining and proposed end-of-mining topography was used to guide landform design. A risk-based design approach was adopted based on the likelihood and consequence of closure landform failure. For relatively minor failure consequences (e.g. scour of the toe of a rehabilitated waste dump) more frequent events were used as the design event. Rarer events were used to design controls aimed at avoiding major consequences, such as creek capture, where a natural watercourse scours a path into a mine void effectively terminating downstream flow. These designs informed a closure strategy involving partial pit backfill and scour management controls on landforms, which has been developed to leave a suitable post-mining landform.
\end{abstract}

Keywords: flood management, hydrological modelling, creek, closure

\section{Introduction}

This case study is based on an iron ore mine located in the Pilbara region of Western Australia. It is an open cut operation utilising conventional drill-and-blast and load-and-haul mining methods. The mine site is a historical site that commenced operations in 1972 and is currently undergoing internal evaluation for expansion.

The mine site comprises a series of open cut pits, mineral waste dumps, a waste fines storage facility (WFSF), land bridges (or elevated haul roads) and associated infrastructure. Two large ephemeral creeks, here within referred to as Creek East and Creek West, traverse through the mine, and landforms are positioned in close proximity to these creeks (Figure 1). Mining disturbs less than $1.5 \%$ of the combined Creek West and Creek East catchment area of $2,470 \mathrm{~km}^{2}$. The closure implications of pits, waste dumps and land bridges in relation to the creeks, and surface water flows and subsequent flood events, are better understood today than in the early 1970s. This paper describes how the flood risk locations were identified, the methods employed to assess the risk, challenges posed for rehabilitation and closure of these landforms and predicted closure outcomes. 


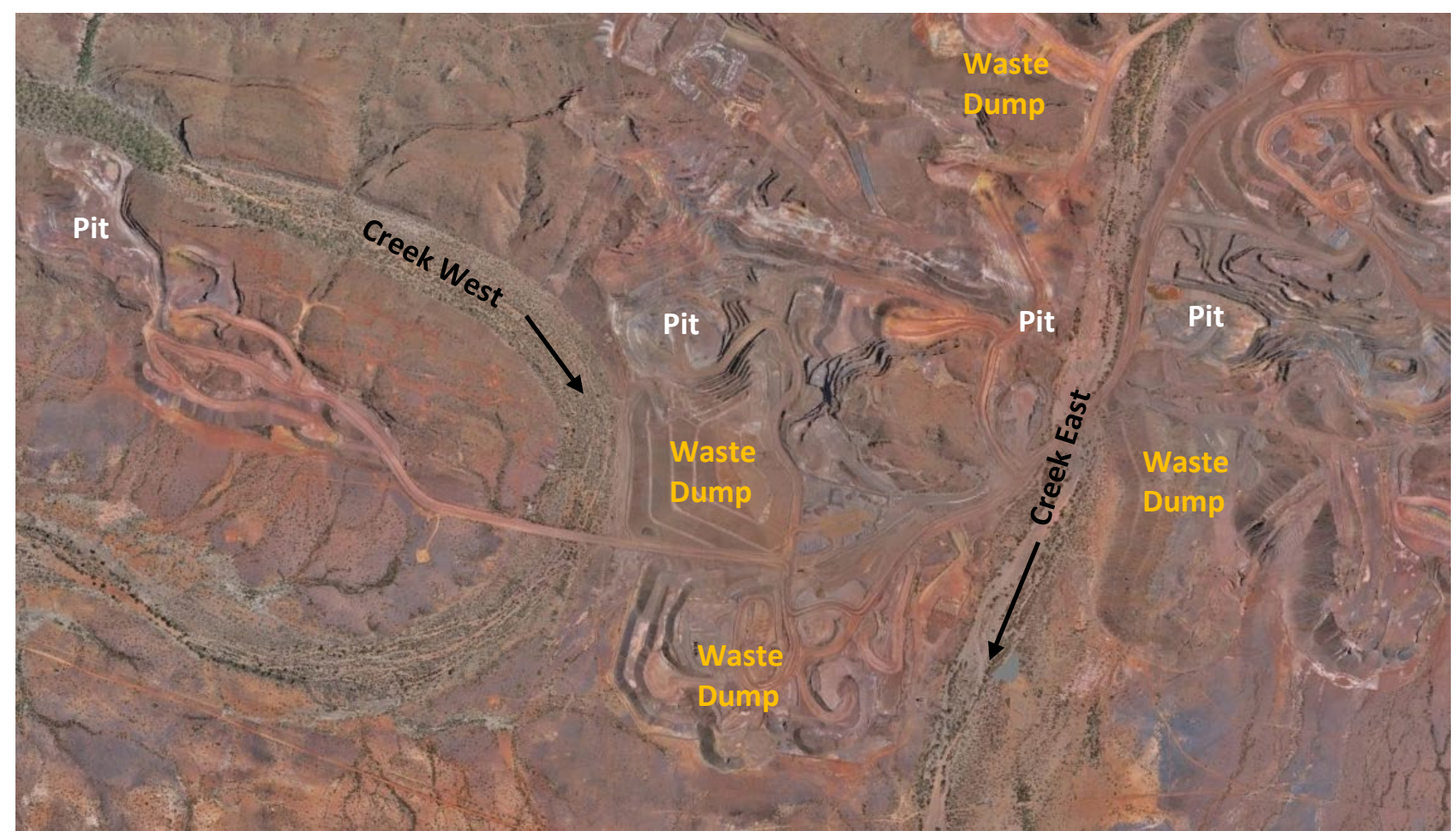

Figure $1 \quad$ Mine footprint and creeks

\section{Climate and surface hydrology}

Landform design and rehabilitation success are influenced by climatic factors such as evaporation and the intensity, frequency and duration of rainfall events. The mine site is situated in a region that is characterised as arid tropical with two distinct seasons; hot wet summers and cool dry winters. Mean daily maxima temperatures range from $41^{\circ} \mathrm{C}$ in summer to $25^{\circ} \mathrm{C}$ in winter (Bureau of Meteorology 2017).

Precipitation occurs predominately in summer, with major rainfalls associated with tropical cyclones, tropical lows and convective thunderstorms. The months of September, October and November have the lowest average rainfall and January, February and March have the highest average rainfall (Figure 2). Annual total rainfall is also highly variable, as evidenced by historical data dating back to 1974 (Figure 3).

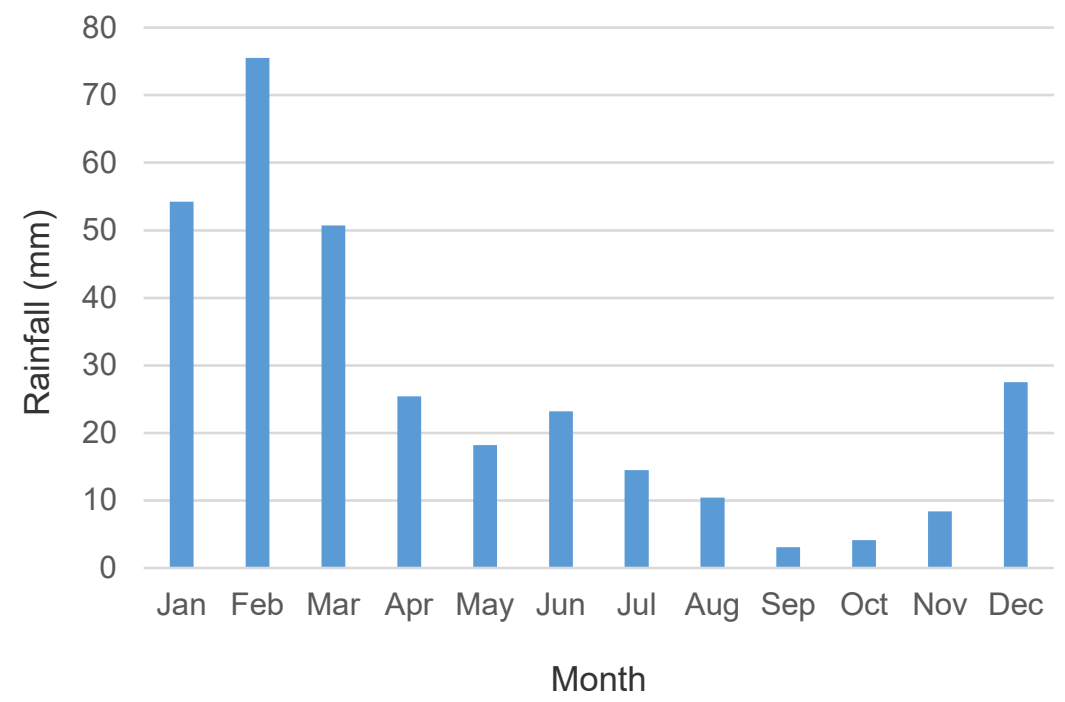

Figure 2 Mean monthly rainfall (mm), for Bureau of Meteorology station 007185 from 1974 to 2017 (data sourced from Bureau of Meteorology 2017) 


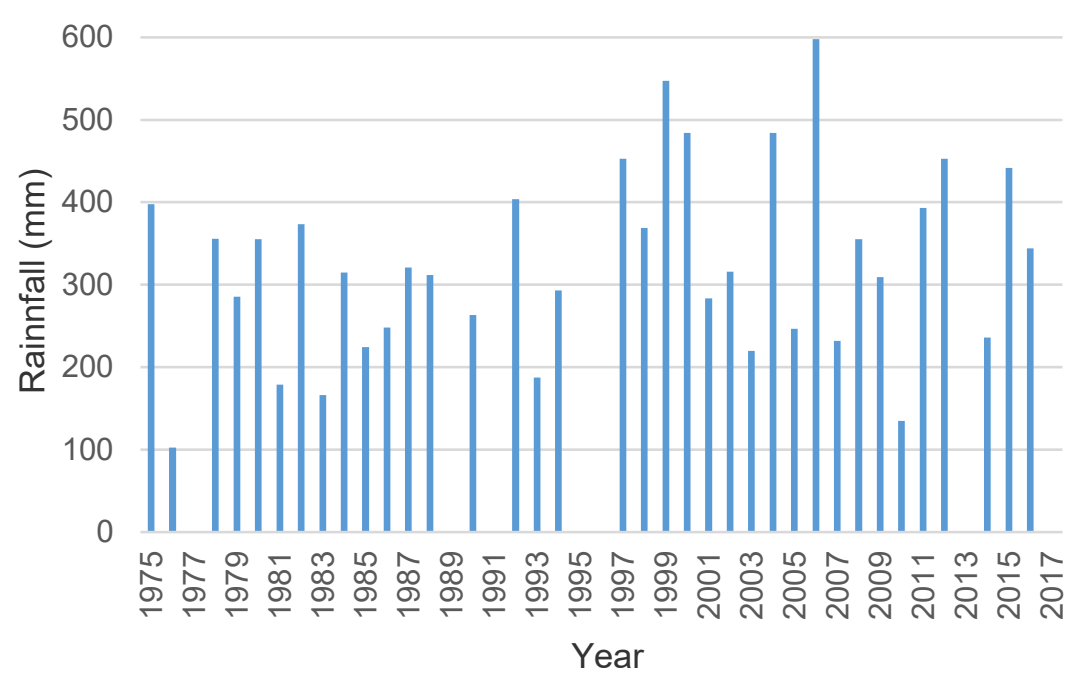

Figure 3 Historical annual rainfall ( $\mathrm{mm}$ ) from 1975 to 2016 at Bureau of Meteorology station 007185. Gaps in data represent incomplete datasets (data sourced from Bureau of Meteorology 2017)

Most tropical cyclones are observed during the late summer, occurring between November and May. In inland areas, tropical cyclones can produce damaging wind gusts in excess of $170 \mathrm{~km}$ per hour, with heavy rains resulting in regional flooding. Five tropical cyclones are expected, on average, to form off the coast of the Pilbara each year, with two expected to make landfall (Bureau of Meteorology 2019a).

One of the greatest impacts arising from tropical cyclones is flooding from heavy rainfall. Flooding is enhanced when multiple tropical lows occur within a few weeks of each other. One of the highest ever floods recorded along the Ashburton River occurred in February 1997, when a slow moving tropical low moved over the west Kimberley, Pilbara and Gascoyne regions causing rainfall in excess of $400 \mathrm{~mm}$ in parts. In December 1975, Cyclone Joan caused over $400 \mathrm{~mm}$ of rain near its track, the highest rainfall being $591 \mathrm{~mm}$ at Marandoo (Bureau of Meteorology 2019b). In addition, local thunderstorm activity that is not associated with cyclonic activity can contribute to localised flash flooding.

Thirteen cyclones/tropical lows have passed within the Creek East and Creek West catchments during the monitoring period (1906 to present). Additionally, cyclones within reasonable proximity of the catchment, approximately $300 \mathrm{~km}$, have potential to influence creek flow within the catchment. In recent history, the flood events experienced at the mine site have been considered to be minor in the context of possible rainfall event magnitudes that are modelled within this paper. Most recently, Cyclone Monty and Cyclone Stan caused flooding of the creek systems in 2004 and 2015, respectively. The track of these cyclones did not navigate directly through the mine site, however they were in close enough proximity to cause heavy rains within the catchment and significant creek flows through the mine site. Flooding associated with Cyclone Monty and Cyclone Stan are shown in Figure 4. 

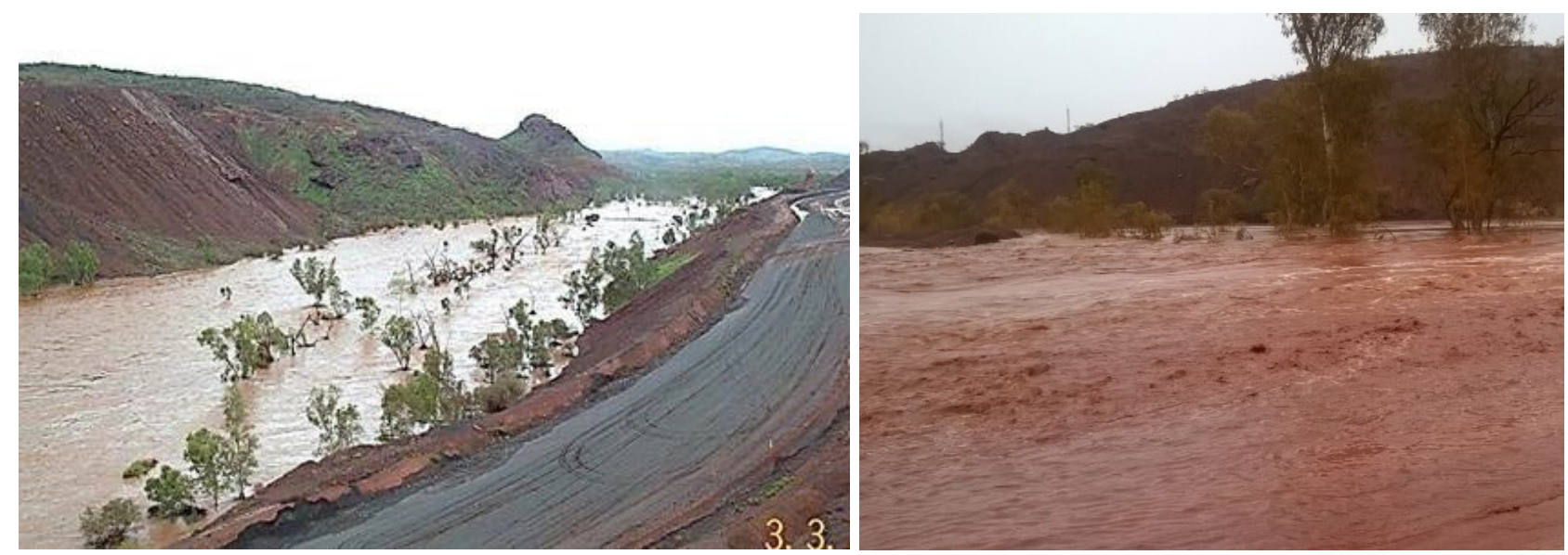

Figure 4 (a) Cyclone Monty (2004) and associated flooding of Creek East; (b) Cyclone Stan (2015) and associated flooding of Creek East

The surface hydrology of the region is determined by climatic conditions and local catchment characteristics. All streams in the area of the mine site are ephemeral and are dry for most of the year, only flowing after substantial rainfall events.

Creek East is the larger of the two creeks that traverse through the mine footprint and is located in the centre of the mining area before continuing its path downstream and discharging into the Ashburton River. Creek West is a smaller tributary of Creek East and drains through the western portion of the mine, joining Creek East approximately $12 \mathrm{~km}$ southwest of the mine footprint.

\section{$3 \quad$ Identification of flood risks to mining areas}

The impact of major flooding on mine landforms was identified as a key risk for closure during a closure risk assessment for the mine site. The Department of Mines, Industry Regulation and Safety (DMIRS) also identified this risk during a site inspection and requested further information on the proposed closure management strategies. As a result of these risk assessments, a closure objective for the mine is to maintain downstream surface water flows of the creeks off-lease. To achieve this full or partial capture of creeks through uncontrolled scour redirecting the creek into mine voids must be prevented.

The post-mining landforms and the potential impact of creek flood events on these landforms were assessed as part of the triennial submission of the mine closure plan (MCP). A team comprising technical experts from the Rio Tinto water resource evaluation, mine planning, survey and closure groups provided expertise and facilitated this assessment. Hydrologic modelling has been used to describe the catchment response to rainfall and estimate peak flow hydrographs for a range of flood magnitudes. Hydraulic surface water modelling has been used to describe the creek system response to flooding and estimate flood depths and velocities within the channel and overbank areas, including the influence of flooding on pits and waste dumps located within the flood zone. The hydraulic models used in this assessment considered both flood inflows from the large creeks flowing through the mine site, and incidental rainfall falling directly on the mine and adjacent areas. Hydraulic modelling estimates for surface water depth and velocity were derived for a range of flood event magnitudes. Risk locations were identified from the flood model results and classified as areas where:

- The creeks could flow into pit voids; and/or

- Post-mining landforms (waste dumps and land bridges) are subject to high velocities and require erosion protection. 
Flood modelling impact assessments of the creeks were conducted on two mine footprint scenarios and these scenarios are described further:

- Conceptual post-mining landform without mine expansion.

- Conceptual post-mining landform with mine expansion. This included expansion to existing pits and additional mineral waste dumps.

\section{$4 \quad$ Risk-based design}

A risk-based design approach has been adopted for the assessment of potential impacts (such as creek capture by pits and closure landform scour) arising from any potential inadequate surface water management and subsequent selection of potential mitigation solutions for the mine closure plan.

As outlined by the general methodologies described by Australian Rainfall and Runoff (ARR) (Ball et al. 2019), an understanding of potential flood behaviour across the post-mining surface was established for a range of flood events, to enable an informed risk-based decision process in the selection of possible mitigation options. For relatively minor failure consequences (e.g. scour of the toe of a rehabilitated waste dump) more frequent events were used as the design event. Rarer events were used to design controls aimed at avoiding major consequences, such as creek capture, where a natural watercourse scours a path into a mine void effectively terminating downstream flow.

To assess a range of flood events, three representative rainfall event magnitudes were applied to Creeks East and West and the resultant levels and velocities were assessed on the adjacent mine landforms. The representative rainfall events were selected to sit within the broad definitions of frequency defined by ARR2019 (Ball et al. 2019), as follows:

- Rare flood event.

- Very rare flood event.

- Extreme flood event.

These event magnitude scenarios were considered appropriate to assess the possible range and severity of flooding and the long design life of the closure landforms. In comparison, recent events discussed in Section 2 are considered frequent.

\section{$5 \quad$ Hydraulic modelling to identify flood risk areas}

Hydraulic modelling of the creeks and adjacent mining area was undertaken via a staged approach:

1. An initial flood modelling assessment based on end of mine life terrain without mine expansion landforms and no risk mitigation, to enable identification of key risk areas.

2. An indicative flood mitigation scenario to assess potential management solutions required to prevent unacceptable flood risk occurring, across post-mining landforms, without mine expansion.

3. Further flood modelling based on the end of mine life terrain comprising the conceptual postmining landform, assuming the proposed mine expansion had been completed, to assess the maximum extent of potential management solutions. This stage forms the basis of the development of conceptual designs for mine closure flood management, and is currently ongoing.

\subsection{Post-mining landforms (without mine expansion) without flood mitigation}

This scenario included baseline flood modelling of un-mitigated flood risk, in order to determine maximum likely flood impact arising from inundation of closure voids and identify landforms at risk from scour occurring in floodplains. 
The post-mining terrain was developed using the base topography (taken from 2013 LiDAR data) and overlaying:

- Updated terrain data showing actual changes since 2013.

- Currently planned terrain changes out to end-of-mining.

- Closure landform designs supplied by the mine planning and closure teams.

\subsubsection{Model results}

An inundation map showing predicted flood depths across the post-mining landscape (without mine expansion) resulting from a very rare flood event scenario is presented in Figure 5 . Analysis of flood depth data shows that all pits located adjacent to the creeks are predicted to intercept creek flows in the absence of closure mitigation measures. These pits are depicted by locations 1, 2, 3, 4 and 5 in Figure 5.

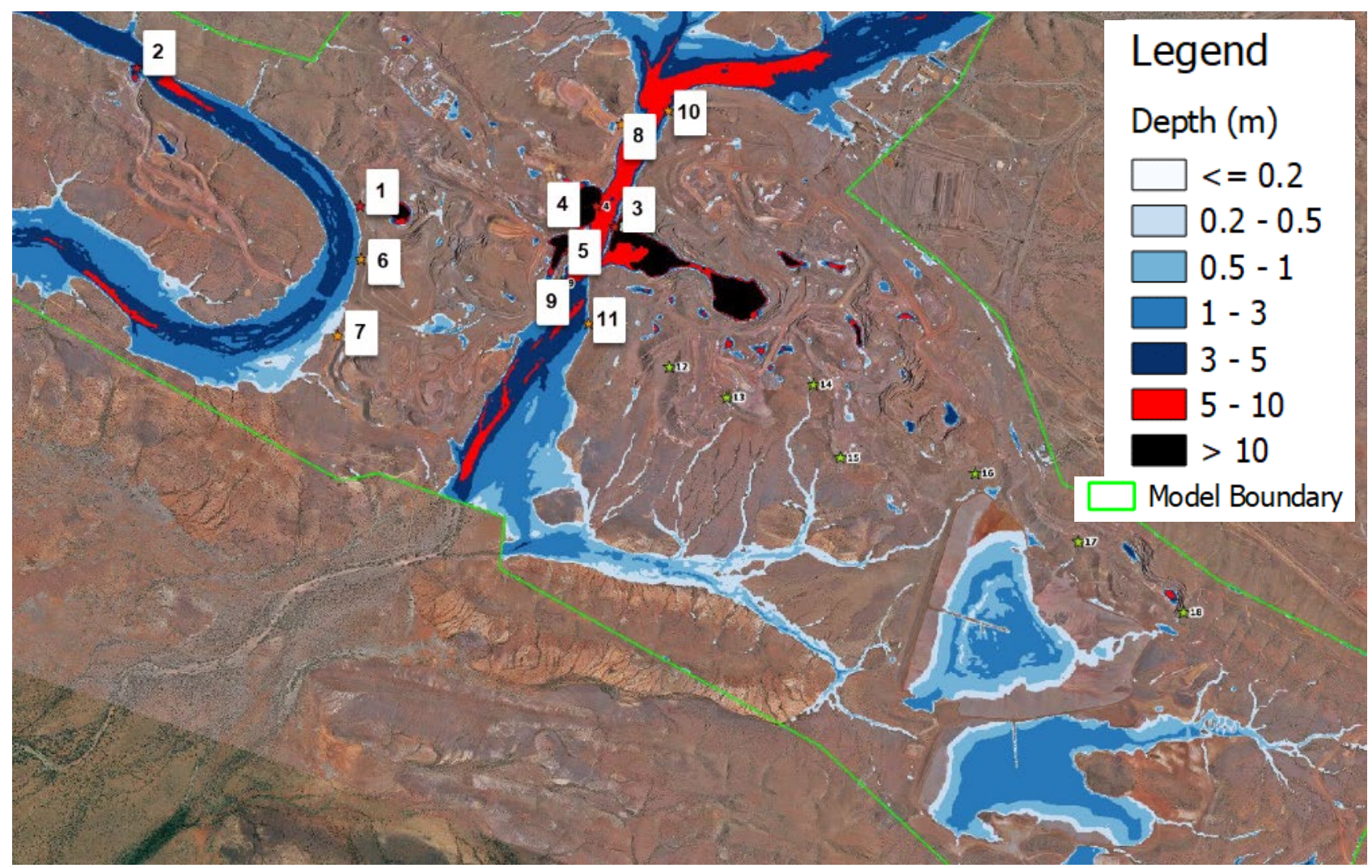

Figure 5 Post-mining flood scenario: risk locations and very rare flood event scenario depths

Peak velocities across the post-mining landscape adjacent to the creeks are anticipated to be moderate to high ( $>2 \mathrm{~m} / \mathrm{s}$ ) at the toe of waste dumps and land bridges located adjacent to creeks during the modelled scenarios at locations 6, 8, 9 and 11 (Figure 6). These locations are at risk of scour erosion without closure mitigation prescriptions. 


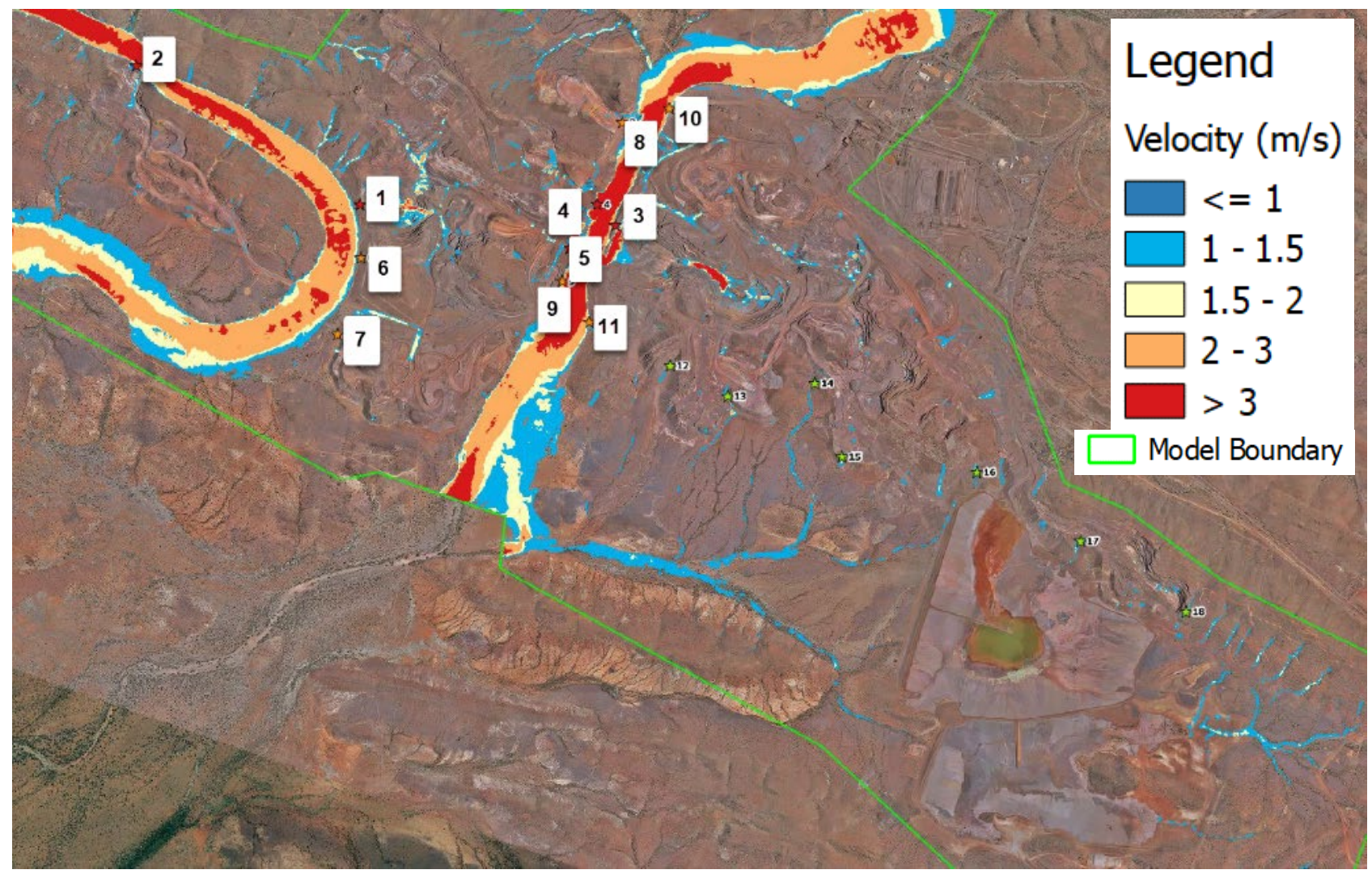

Figure 6 Post-mining flood scenario: risk locations and very rare flood event scenario velocity

\subsection{Post-mining landforms (without mine expansion) with flood mitigation}

This scenario included flood modelling of bunded pits, for the post-mining landforms without mine expansion. Bunding was set to a nominal level well above the extreme flood event to prevent creeks flowing into pit voids. The resulting water level estimate was used to set the actual flood levee design requirements.

The bunded pits scenario used hypothetical (i.e. no design consideration of bund construction profile or methodology) bunds to prevent floodwaters from entering the adjacent pit voids. This scenario was intended for use in providing flood levels to guide closure landform design.

\subsubsection{Model results}

An inundation map showing predicted flood depths across the post-mining landscape (without mine expansion) including hypothetical flood bunds, resulting from a very rare flood event scenario is presented in Figure 7. Analysis of flood depths show that all pits located adjacent to the creeks are protected from interception of creek flows. Some inundation occurs as a result of rainfall and runoff from local upstream catchments within the model domain. These pits are depicted by locations 1, 2, 3, 4 and 5 in Figure 7. Modelled flood elevations increased for the bunded scenario on average by $0.2 \mathrm{~m}$ for the very rare event and $0.6 \mathrm{~m}$ for the extreme flood event.

The bunding of the pit crests resulted in moderate increases to the predicted peak velocities within the main channels (Figure 8). As identified in the baseline modelling, landforms adjacent to the creeks are at risk of scour erosion without closure mitigation solutions. Closure mitigation options include possible relocation/redesign of the closure landforms (waste dumps and land bridges) such that they are outside of the rare event. At this site, flood bunds adjacent to pits double as abandonment bunds, so partial backfill of the at-risk mine voids means the zone of instability (and therefore the abandonment bund alignment) can be moved further away from the main channel. 


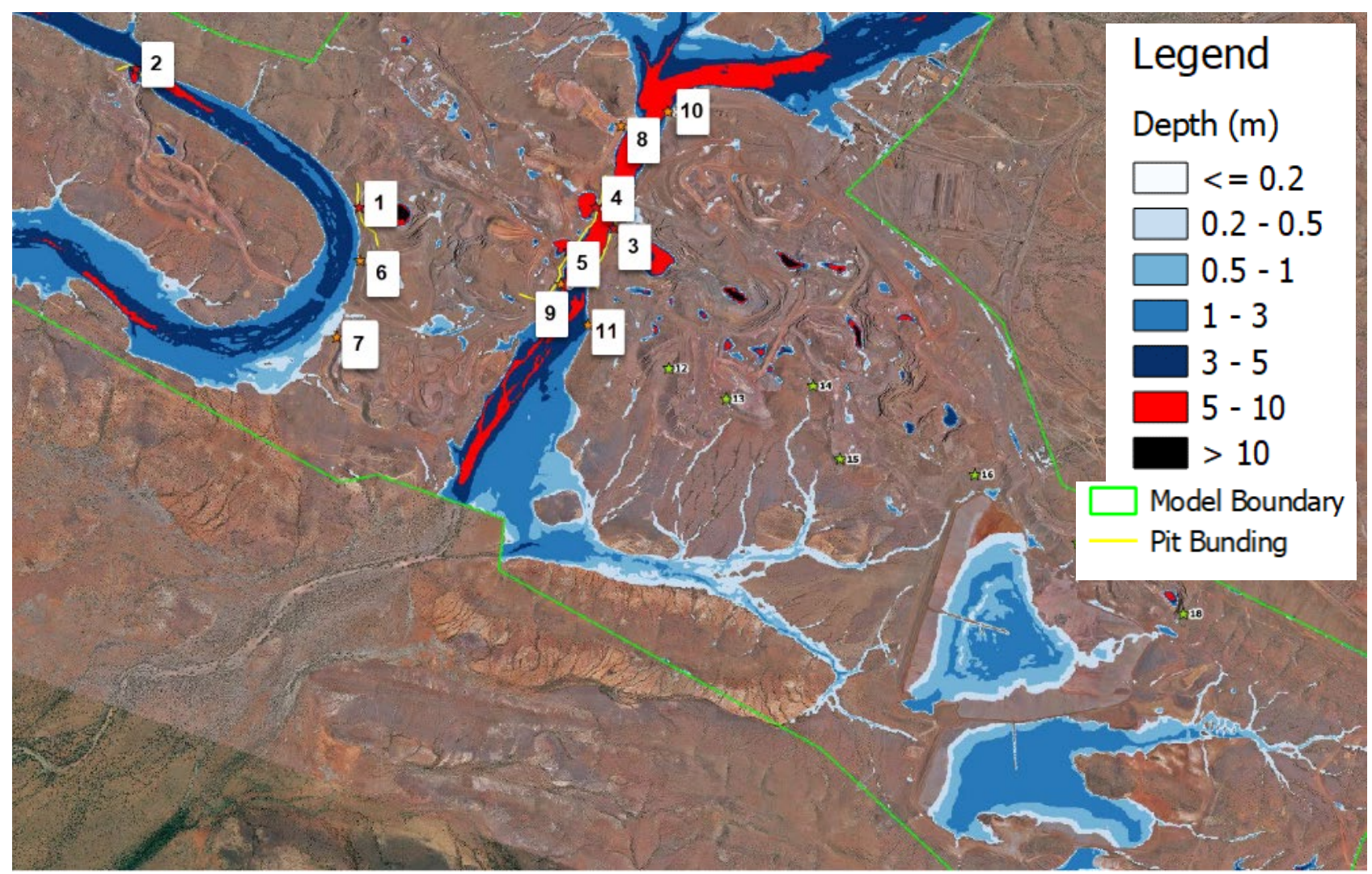

Figure 7 Post-mining flood scenario with hypothetical flood bunds: very rare flood event scenario depths

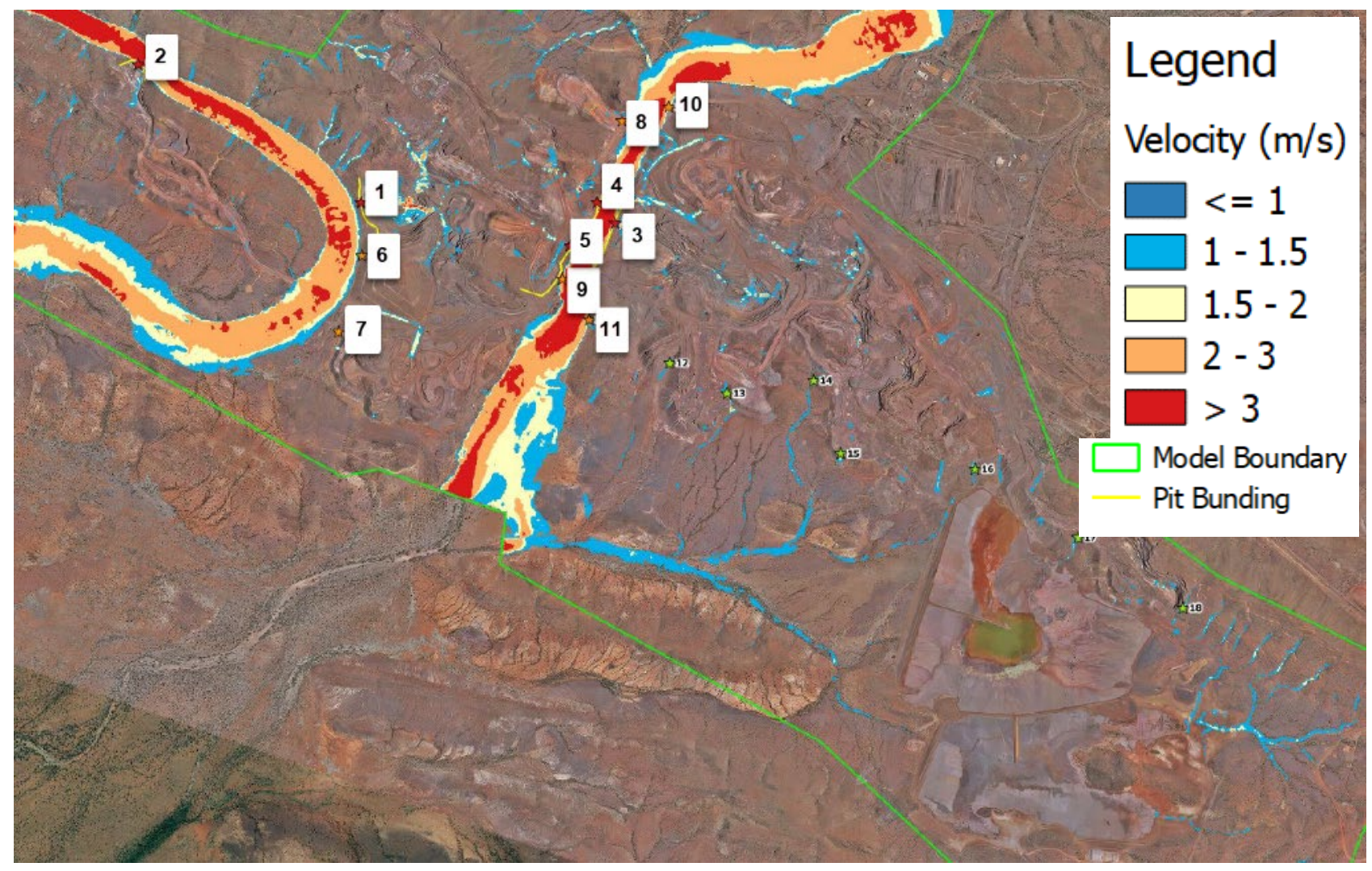

Figure 8 Post-mining flood scenario with hypothetical flood bunds: very rare flood event scenario velocity 


\subsubsection{Partial backfill}

In areas where risk of pit flooding was identified by the flood modelling, partial backfill of the pits was developed to a conceptual design stage. The partial backfill involved a buttress design such that a flood bund extended above the adjacent topography to exceed slightly the predicted flood elevation under the extreme rainfall event. Figure 9 shows the indicative backfill arrangement with conceptual buttress designs for stability of the proposed earthworks design.

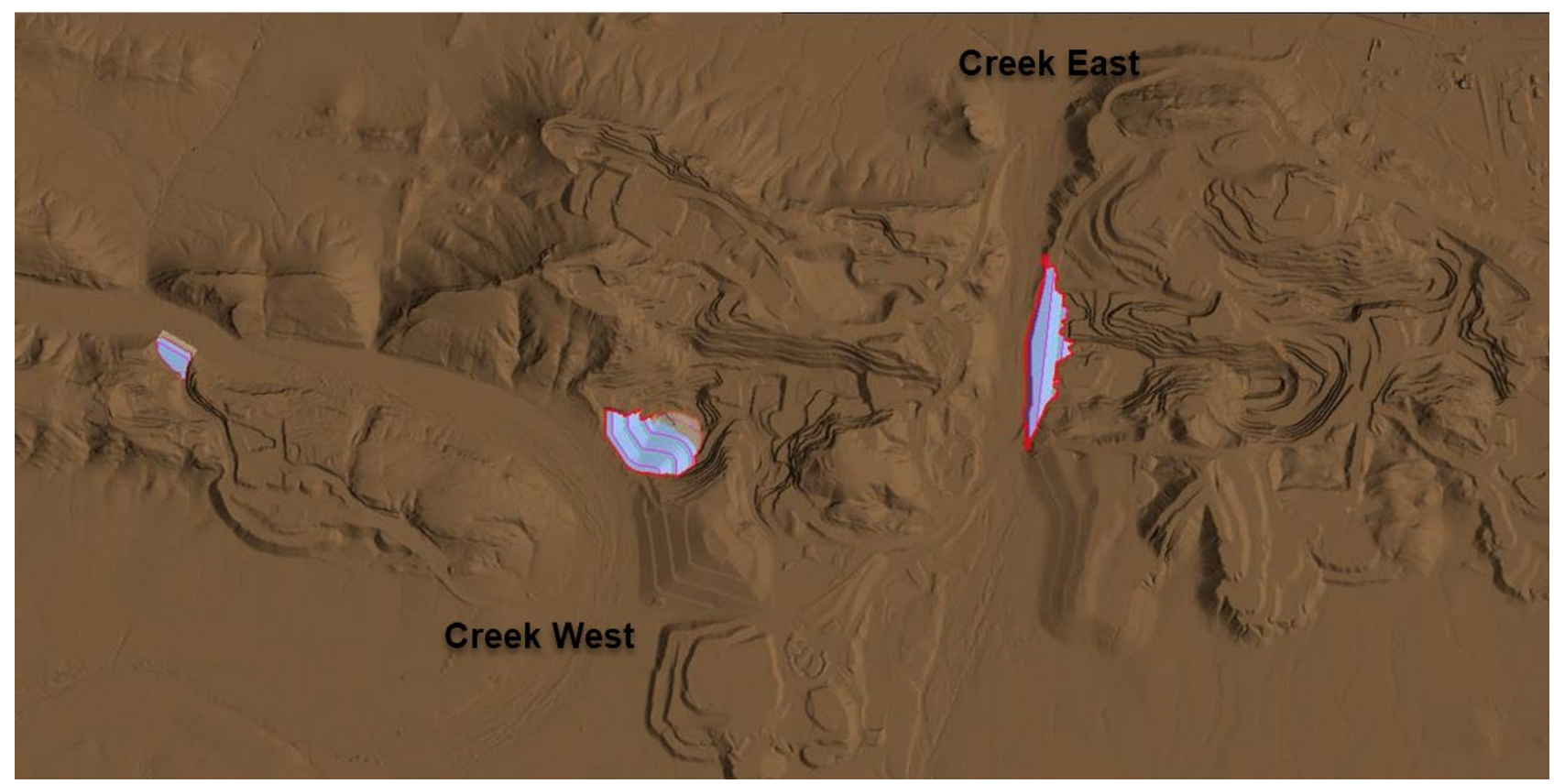

Figure 9 Conceptual partial backfill closure designs for pits to prevent creek interception. Blue areas depict conceptual backfill designs with buttressing

\subsection{Post-mining landforms (with mine expansion)}

A proposal was developed to expand mining at the site, altering the post-mining landform. Additional flood modelling and landform design was undertaken on terrain comprising the conceptual post-mining landform, assuming the proposed mine expansion had been completed. Development of the post-mining terrain under the expanded mine scenario considered the findings from previous flood modelling results as described in Section 5.2, and in some instances closure options were incorporated as part of the expansion, specifically:

- Waste dumping strategy and schedule during mine operations considered partial pit backfill to some pits.

- New waste dumps and land bridge footprints placed outside of the rare flood event extent boundary.

Closure landform design under the expansion scenario incorporated:

- Partial removal of existing waste dumps and land bridges so that the toes of these landforms were outside of the rare flood event extent boundary. Landform surface modelling was conducted on pre-mining topography, to determine the natural rare flood event extent without mine influence.

- Modelling of the three rainfall event magnitudes (rare, very rare and extreme) using the revised terrain.

Initial results indicate that the impact of flood events on mine landforms has been reduced with the updated mine plan. In particular, some pits that previously intercepted creek flow under the very rare flood event no longer intercepted creek flows in the revised terrain. The impact of erosion scour was also reduced due to relocation of mine landforms outside of the rare flood extent boundary. At the time of writing this paper, the 
modelling and assessment of the post-mining landforms (with mine expansion) was still in draft format, therefore results are considered indicative only and figures have not been presented.

\section{Conceptual closure designs}

At the time of writing this paper, conceptual closure designs had been prepared, however detailed closure designs for pits, waste dumps and land bridges located on creek lines were not yet finalised. Bunding and/or partial pit backfill have been considered as options on closure to prevent creek interception by at-risk pits, for those pits not already backfilled during mine operations.

Conceptual backfill designs have been proposed (Figure 9) and these take into consideration minimum height to prevent creek interception, batter berm configuration for adequate buttressing, slope angle and width. Due to the proximity of these pits to large creeks, the resulting high risk of creek interception and the constructability of the structures, the backfill has been designed to raise the final landform above the estimated level of the extreme flood event. These designs will be refined prior to closure and factors such as geotechnical stability and type of construction material required for long-term stability will be addressed. These designs are indicative only and subject to revision based on Rio Tinto's ongoing assessment of the merits and implications of adopting the extreme event scenario for final landform design for these pits.

Mitigation options for waste dumps and land bridges located adjacent to creeks that are at risk of scour may include rock armouring of potential scour zones or removal of waste material. Management of these erosion risks will be addressed within the detailed closure designs.

Incorporation of closure options into the mine plan as part of the expansion will enable closure solutions to be inbuilt and constructed during mine operations. For example, backfilling a pit located adjacent to Creek East during mine operations will have a number of benefits and these include:

- Managing flood risk during mine operations.

- A shorter haulage distance resulting in lower operational costs.

- A reduction in environmental and closure risk.

- A reduction in closure liability and associated earthmoving costs at closure.

- A reduction in the disturbance footprint as waste will be stored in-pit and not required to be stored externally.

- Ability to use the backfilled footprint during mine operations for infrastructure purposes.

\section{Conclusion}

The heavy, intense rainfall and subsequent flood events experienced in the Pilbara makes climatic factors a key influence on the stability of closure landforms. The mine footprint, which was initially mined in the early 1970s, presented significant closure challenges, with pits, waste dumps and land bridges located adjacent to creeks. A risk-based approach helped determine which flood magnitude was appropriate for different elements of the landform design.

Due to the potential environmental consequences posed if pits were to intercept surface water flows, and through consideration of the risk-based design approach outlined by ARR2019 (Ball et al. 2019), it was considered appropriate to model a range of rainfall events from rare to extreme, to adequately assess potential risks arising from the proposed closure landforms. The closure strategy focused on maintaining downstream surface water flows off-lease, and possible closure options included partial pit backfill and/or bunding, changes to the mine sequence and/or relocation of proposed closure landforms and/or rock armouring where practicable.

Collaboration between technical experts from a range of disciplines facilitated the identification of flood risk areas and closure management options required for a safe, stable landform post-closure. Following internal 
and regulatory approval for the expansion of mining operations at this mine, further closure solutions may be designed into the mine plan, aimed to result in an improved closure outcome and a reduction in closure costs.

\section{References}

Ball, J, Babister, M, Nathan, R, Weeks, W, Weinmann, E, Retallick, M \& Testoni, I (eds) 2019, Australian Rainfall and Runoff: A Guide to Flood Estimation, Commonwealth of Australia.

Bureau of Meteorology 2017, Bureau of Meteorology, Perth, viewed 21 September 2017, http://www.bom.gov.au/climate/data/ Bureau of Meteorology 2019a, Bureau of Meteorology, Perth, viewed 5 March 2019, http://www.bom.gov.au/climate/cyclones/ australia/\#tabs=Outlook

Bureau of Meteorology 2019b, Bureau of Meteorology, Perth, viewed 5 March 2019, http://www.bom.gov.au/cyclone/history/ wa/pilbara.shtml 
